\title{
A Stochastic Water Quality Forecasting System for the Yiluo River
}

\author{
H. C. Guo ${ }^{1}$, L. Liu ${ }^{2}$, G. H. Huang ${ }^{2 *}$ \\ ${ }^{1}$ Center of Environmental Sciences, Key Laboratory for Water and Sediment Sciences, MOE, \\ Peking University, Beijing 100871, China \\ ${ }^{2}$ Environmental Systems Engineering Program, Faculty of Engineering, \\ University of Regina, Regina, Sk S4S 0A2, Canada
}

\begin{abstract}
A challenging problem for water quality management in northern Chinese rivers is their high loadings of organic pollutants and suspended solids, leading to complexities in producing effective water quality models. Also, uncertainties exist in many system parameters and their interrelationships. This study aims at developing a stochastic water-quality forecasting system and applying it to the Yiluo River, a tributary of the Yellow River with extremely high sediment and suspended-solid loadings. Extensive investigations of water quality in the river and the related pollution sources and watershed conditions were conducted. A one-dimensional BOD-DO model was developed to simulate water quality in the river, with interrelationships among water quality and the related source and sink conditions being explicated. A stochastic water-quality forecasting system was then developed to reflect random characteristics of many parameters, based on Kalman-filtering and self-adaptive techniques. The developed system was used for predicting DO and BOD levels in the Yiluo River. The results indicated that randomness in many system parameters and their interactions had been effectively handled; the accuracy of state estimation was generally satisfactory.
\end{abstract}

Keywords: Filter, forecast, Kalman, model, pollution, random, river, stochastic, uncertainty, water quality

\section{Introduction}

Water pollution in rivers and streams is acquiring more and more attention in China, along with its rapid economic development and population growth. Water pollution can lead to a variety of impacts on communities and ecosystems. Consequently, it is desired that effective water pollution control strategies with sound environmental and socio-economic efficiencies be identified. Water pollution could be related to a number of factors and processes, with multi-source, multistage, and multi-objective characteristics. Thus, when decisions regarding water quality management are to be made, an integrated consideration that incorporates these factors and processes within a general framework would be useful for effectively reflecting these complexities.

Previously, a number of river-water quality models have been developed for supporting waste-loading allocation, pollution control, and land-use planning in river basins (Orlob, 1992; McCutcheon, 1989). The first water quality model was developed by Streeter and Phelps (1925). The basic principles behind this model include (i) DO is supplied by reaeration and photosynthesis and demanded by respiration and BOD, and (ii) BOD is due to emissions from point and nonpoint sources and could be reduced by oxidation, sedimentation and absorption processes. After that, a number of further studies were undertaken (Thomas, 1948; Thackston \& Krenkel, 1966; Di Toro \& O'Connor, 1968; Young \& Beck, 1974; Shastry et al., 1975;

\footnotetext{
* Corresponding author: Gordon.huang@uregina.ca
}

Fillos \& Swanson, 1975; Rinaldi \& Soncini-Sessa, 1978; Belanger, 1980; Peavy et al., 1985). Various computer software packages were developed, such as DOSAG-I, HSPF, DIURNAL, RECEIV-II, RWQM, RIBAM, STREAM 7B, WQRRS, WASP, QUAL2E, and Mike11 (Brown \& Barnwell, 1987; McCutcheon, 1989).

Typically, many processes associated with water pollution are uncertain in nature (Thomann, 1982; Hobbie \& Tiwaris, 1978). These uncertainties could arise from a variety of causes, such as inherent variability and randomness in natural processes (e.g. hydrological conditions), errors from sampling and measurement processes (e.g. instrumental noise), modeling assumptions that are unrealistic, and lack of data for effective research works. For example, variations of flow velocity in a river due to random turbulence can cause dispersion of suspended particles and dissolved compounds to various directions. Although the majority of water quality models developed so far were deterministic, an increasing number of them considered uncertainties in recent years, such as methods of Monte Carlo simulation, Markov chain, Kalman filter, and Fokker-Planck equation (Loucks \& Lynn, 1966; Shih, 1975; Beck \& Young, 1976; Tiwaris et al., 1978; Finney et al., 1982; Dewey, 1984; Leduc et al., 1986; Ponnambalam \& Curi, 1991). Finney et al. (1982) and Zielinsky (1989) used the Ito rule for determining the first- and second-order moment equations for a set of stochastic differential equations associated with water-quality models. Tung and Hathorn (1988) and Song and Brown (1990) used Taylor series to determine moment equations for a set of random differential 
equations in DO models. These stochastic methods improved upon deterministic ones through effective reflection of uncertainties that exist in many modeling components.

As an extension of the previous efforts, this study focuses on the development of a stochastic water-quality forecasting system for the Yiluo River, a tributary of the Yellow River with extremely high sediment and suspended-solid loadings. A modified Dobbins BOD-DO model is developed to simulate water quality in the river. Interrelationships among water quality and the related pollution sources and watershed conditions are analyzed. The developed model is calibrated through examination of historical data and implementation of specific field studies. A stochastic water-quality forecasting system is then developed based on Kalman-filtering and self-adaptive techniques (Kalman, 1960). Random characteristics of many system parameters and their interrelationships are taken into account through adding noise terms to modeling equations. The developed forecasting system is used for predicting DO and BOD levels in the Yiluo River. Historic data of river flow and water quality in dry-, wet- and level-seasons were used for parameter estimation and result verification.

\section{Overview of the Study System}

Investigation of the study river system was carried out through efforts of data collection, on-site environmental monitoring, database development, and laboratory analysis. A number of crucial factors, including hydrological and geological features, source distribution, pollutant emission and water quality, were examined. The results provided bases for further modeling studies.

\subsection{Geographical and Hydrological Conditions}

The Yiluo River is located in northern China. It is the largest tributary of the Yellow River in its lower reach, covering a watershed area of $18,881 \mathrm{~km}^{2}$. It consists of three sections, including two upper branches [the Yihe Branch (YB) and the Luohe Branch (LB)] and one lower main stream (LMS) (Figure 1). Among them, YB has a length of $410 \mathrm{~km}$, and LB extends for approximately $265 \mathrm{~km}$. These two branches confluence at the Yanshi County. The LMS starts at the confluence of YB and LB and extends for approximately 37 $\mathrm{km}$ to reach the Yellow River. The study river section has a length of $62 \mathrm{~km}$ starting from the Xinqiao Bridge at the Luohe Branch down to the Town of Shihuiwu beside the LMS.

There are three hydrological monitoring stations in the study section, including the Baimasi Station for the Luohe Branch, the Longmen Station for the Yihe Branch, and the Heishiguan Station for the LMS (Figure 1). The yearly average flow rates for LB and LMS are 62 and $100 \mathrm{~m}^{3} / \mathrm{s}$, respectively; and their annual runoff loadings are $1.943 \times 10^{9}$ and $3.154 \times 10^{9} \mathrm{~m}^{3}$, respectively. Runoff loadings within the study watershed have significant temporal variations, with their values in wet (July to October), dry (June and December to March) and level (April, May and November) seasons ac- counting for $60 \%, 15 \%$ and $25 \%$, respectively, of the annual total.

Since the Yiluo River is located at the North China Plain, it has characteristics of high solid loading, low slope $(0.035 \%)$, and low velocity $(0.3$ to $0.6 \mathrm{~m} / \mathrm{s}$ at the Baimashi Station, and 0.2 to $0.4 \mathrm{~m} / \mathrm{s}$ at the Heishiguan Station). The average suspended-solid (SS) contents in water are 4.94, 3.21, and 1.93 $\mathrm{kg} / \mathrm{m}^{3}$ at the Baimasi, Heshiguan, and Longmen Stations, respectively, leading to high sedimentation rates onto the river bed. The yearly average water temperatures are $14.1^{\circ} \mathrm{C}$ at the Baimasi Station and $15.4{ }^{\circ} \mathrm{C}$ at the Heishiguan Station, with significant seasonal variations. The highest temperature occurs in July with a monthly average of 25.2 to $26.6{ }^{\circ} \mathrm{C}$, while the lowest appears in January (monthly average $=2.1$ to 2.5 $\left.{ }^{\circ} \mathrm{C}\right)$.

\subsection{Water Pollution Concerns}

The Yiluo River Watershed contains the Luoyang City, the Yanshi County, and the Gong County, where many industries exist; also, several smaller towns and villages are close to the river. Municipal and industrial wastewater from these population centers is mostly discharged to the river, without even primary treatment, through 8 outlets as shown in Figure 1. Among these outlets, one is from a chemical fertilizer industry, two from pulp and paper plants, and the remaining from municipal and other industrial sources. The average BOD emission rate from all municipal and industrial sources was 20,500 kg/d, with the Luoyang City, the Gong County, and the Yanshi County contributing $47.1 \%, 38.7 \%$, and $14.2 \%$, respectively. Table 1 gives BOD concentrations and emission rates at the eight outlets.

Table 1. Average BOD Loadings from Eight Wastewater Discharge Outlets

\begin{tabular}{lcccccccc}
\hline Outlet & D1 & D2 & D3 & D4 & D5 & D6 & D7 & D8 \\
\hline $\begin{array}{l}\text { BOD } \\
(\mathrm{mg} / \mathrm{L})\end{array}$ & 23.4 & 155.0 & 308.0 & 86.9 & 214.0 & 253.0 & 309.0 & 112.0 \\
$\begin{array}{l}\text { BOD } \\
(\mathrm{kg} / \mathrm{d})\end{array}$ & 2822 & 3350 & 3437 & 1493 & 1411 & 2712 & 2279 & 2949 \\
\hline
\end{tabular}

Note: D1 - Jianhe; D2 - Luoyang Pulp and Paper Plant; D3 - Chanhe; D4 - Yanshi Fertilizer Plant; D5 - Yuetan Pulp and Paper Plant; D6 Huiguozheng; D7 - Ershilipu; D8 - Shihedao

To gain insight into variations of water quality along the river, 10 monitoring intersections were monitored (Figure 1). Among them, two were at the Baimasi and Heishiguan Hydrological Stations, and the others were close to the eight wastewater discharge outlets. Two monitoring programs (MP1 and MP2) were initiated for investigating hydraulic characteristics (e.g. flow, velocity, and depth), water quality (e.g. BOD, DO, COD, and temperature), and source strength (e.g. wastewater flow). 


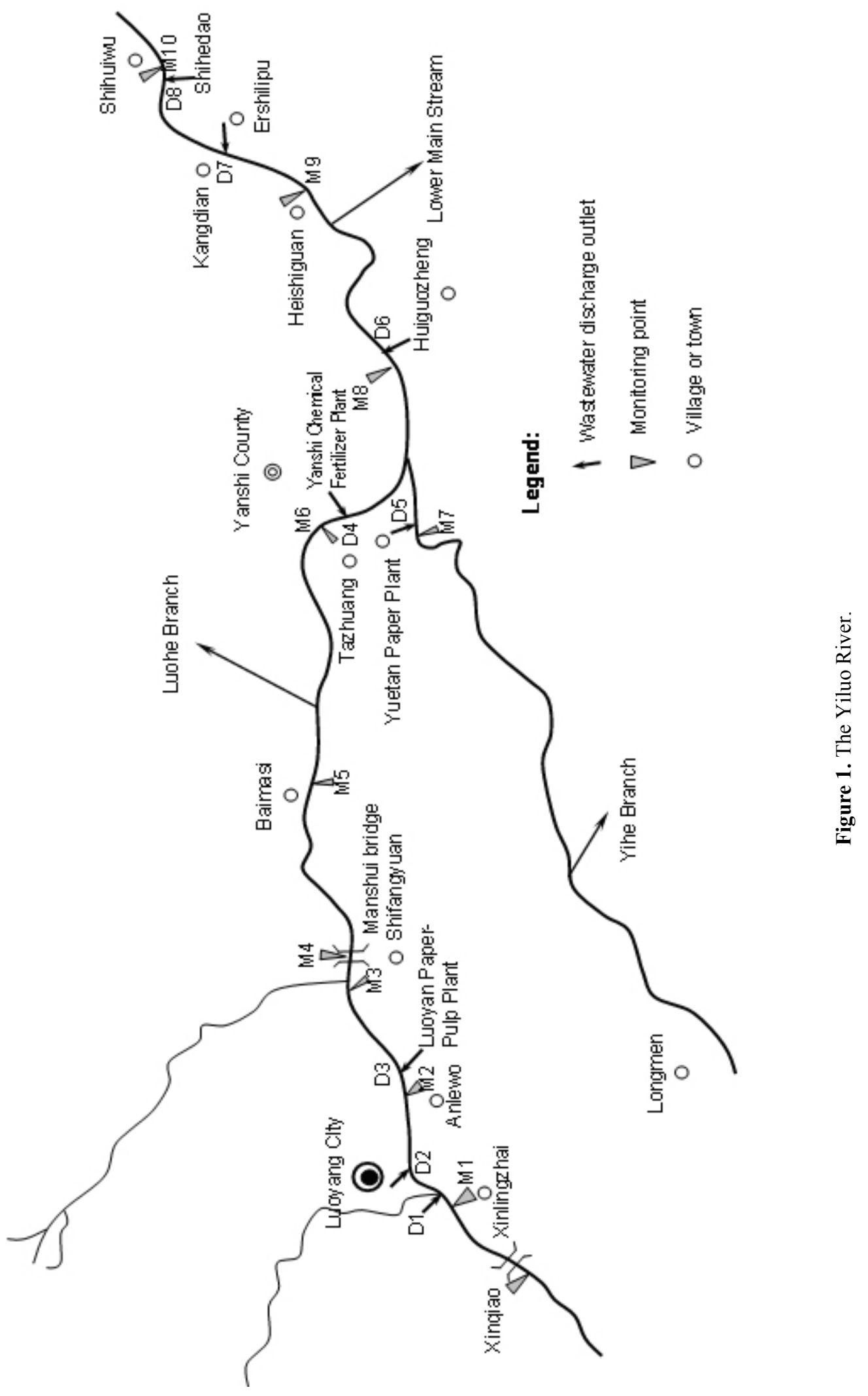




\section{(1) Spatial variations of water quality}

Table 2 presents monitoring results of BOD and DO levels in different intersection. It is indicated that the BOD levels vary significantly along the river. BOD concentration at Station M1 is below $2.0 \mathrm{mg} / \mathrm{L}$, indicating satisfactory water quality at the river's upstream. Three wastewater discharge outlets (i.e. D1, D2 and D3) were located in the Luoyang City (Figure 1); the total BOD loading from them is $9,645 \mathrm{~kg} / \mathrm{d}$, causing significant deterioration of water quality downstream. The highest BOD concentration was encountered at the Manshui Bridge (M4), with an average of $75.1 \mathrm{mg} / \mathrm{L}$, where the DO dropped to zero. Since there was no additional wastewater discharge outlet between M4 and M5, water quality gradually improved due to natural attenuation. The average BOD concentration at Station M5 was reduced to $3.32 \mathrm{mg} / \mathrm{L}$. The section between M5 and M9 received small amounts of wastewater from the Yanshi Chemical Fertilizer Plant and the Yuetan Paper-Pulp Plant (D4 and D5), where BOD levels fluctuated within a small range. However, a rapid increase of BOD level occurred in section M9 to M10 due to the discharge of over $5,000 \mathrm{~kg} / \mathrm{d}$ of BOD from the Ershilipu and Shihedao. At M10, the maximum BOD concentration reached 23.9/L. Figure 2 presents the variations of BOD concentrations along the river.

Table 2. BOD Concentrations $(\mathrm{Mg} / \mathrm{L})$ and DO Saturation Levels (\%) at Nine Monitoring Stations

\begin{tabular}{lllllll}
\hline \multirow{2}{*}{ Station } & \multicolumn{2}{c}{ Average } & \multicolumn{2}{c}{ Maximum } & \multicolumn{2}{c}{ Minimum } \\
& BOD & DO & BOD & DO & BOD & DO \\
\hline M1 & 1.59 & 91.6 & 2.55 & 130.0 & 0.39 & 72.8 \\
M2 & 3.03 & 82.4 & 7.89 & 99.0 & 0.90 & 61.0 \\
M3 & 6.15 & 76.7 & 15.60 & 103.0 & 1.64 & 43.0 \\
M4 & 18.99 & 53.4 & 75.10 & 95.9 & 1.35 & 0 \\
M5 & 3.32 & 81.6 & 11.20 & 178.0 & 0.79 & 17.6 \\
M6 & 3.65 & 94.0 & 17.40 & 253.0 & 0.67 & 54.1 \\
M8 & 2.75 & 85.5 & 6.11 & 127.0 & 1.38 & 62.8 \\
M9 & 3.59 & 88.5 & 9.35 & 157.0 & 0.54 & 62.0 \\
M10 & 5.99 & 83.1 & 23.90 & 188.0 & 0.56 & 15.5 \\
\hline
\end{tabular}

Note: The data in this table are based on five-year monitoring results.

\section{(2) Seasonal variations of water quality}

Table 3 gives average BOD and DO concentrations at the 10 monitored intersections in different seasons. It is indicated that water quality of the river varied significantly with season. In dry season, the average BOD concentrations at most of the interactions were over $5.0 \mathrm{mg} / \mathrm{L}$; in level and dry seasons, the BOD levels dropped down significantly. The results demonstrate correlations between water quality and flow rate. Figure 3 presents the relationship between BOD levels and flow rates at the Manshui Bridge (M4). It shows that the BOD levels decreased when the flow rates increased.

\section{Modeling Formulation}

\subsection{Identification of Modeling Approach}

Many factors should be considered in identifying the modeling approach, such as data availability, methodology applicability, and desired level of detail for the modeling outputs. Several special features of the study river system are analyzed as follows:

(i) Previous studies on sediment transport indicated that the Yiluo River is in fact a sedimentational section of the entire river (Guan \& Guo, 1985). During wet seasons, the river's flow rates could increase considerably, leading to sediment resuspension. Consequently, large amounts of biodegradable matters can be released from the sediment to the water, causing water-quality deterioration. It is desired that the developed model should be able to reflect these sedimentation-resuspension processes.

(ii) In the study river section, DO concentrations are significantly affected by daily and seasonal temperature variations. With raised temperature, the rates of organism metabolism and waste decomposition will rise accordingly, leading to increased oxygen demand; also, the raised temperature will result in reduced DO solubility in water. Thus, conditions of DO deficiency may occur frequently during summer months. At the same time, the warm season is also associated with high flows that provide more dilution capacity. The developed water quality model should be able to reflect this complexity.

(iii) In the study section, organic SS content affects water quality significantly. It is indicated that $54 \%$ of total discharged BOD at outlet D2 is from organic SS. Thereof, it is desired that the developed model be able to reflect the contribution from organic SS.

Based on the above considerations, the one-dimensional BOD-DO model (Dobbins, 1964) was developed for the study river. The general modeling formulation is as follows:

$$
\begin{aligned}
& V \frac{d L}{d x}=-\left(K_{1}+K_{3}\right) L \\
& V \frac{d C}{d x}=-K_{1} L+K_{2}\left(C_{5}-C\right)+K_{4}
\end{aligned}
$$

where $L$ is biochemical oxygen demand (BOD) $(\mathrm{mg} / \mathrm{L})$; $C$ is dissolved oxygen level (DO) $(\mathrm{mg} / \mathrm{L}) ; C_{s}$ is saturated DO concentration $(\mathrm{mg} / \mathrm{L}) ; K_{I}$ is oxygen consumption coefficient $\left(\right.$ day $\left.^{-1}\right) ; K_{2}$ is oxygen recovery coefficient $\left(\right.$ day $\left.^{-1}\right) ; K_{3}$ is a coefficient related to sedimentation, flocculation, scour, and resuspension of BOD $\left(\right.$ day $\left.^{-1}\right) ; K_{4}$ is rate of oxygen production or consumption through photosynthesis or photorespiration $(\mathrm{mg} / \mathrm{L} \cdot$ day $) ; V$ is flow velocity $(\mathrm{km} /$ day $)$; and $x$ is distance $(\mathrm{km})$.

Within a limited time interval, if variations of flow velocity are insignificant, $V$ can be considered as a constant. Thus, letting $t=x / V$ represents the time for a parcel of water flowing over distance $x$, equation (1) can then be converted to: 


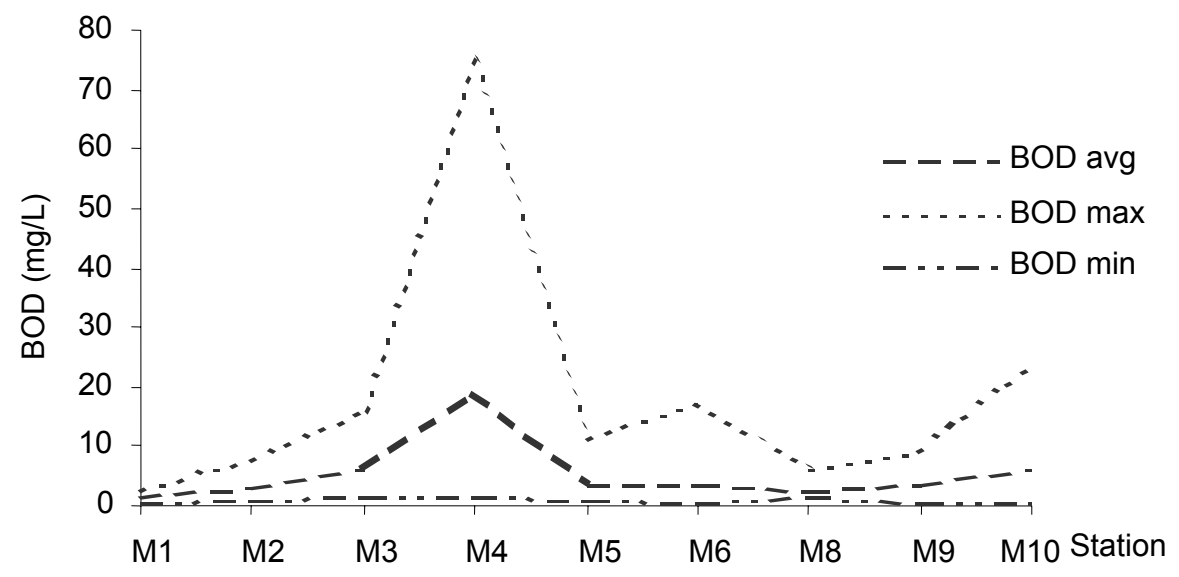

Figure 2. Variations of BOD concentrations along the Yiluo River.

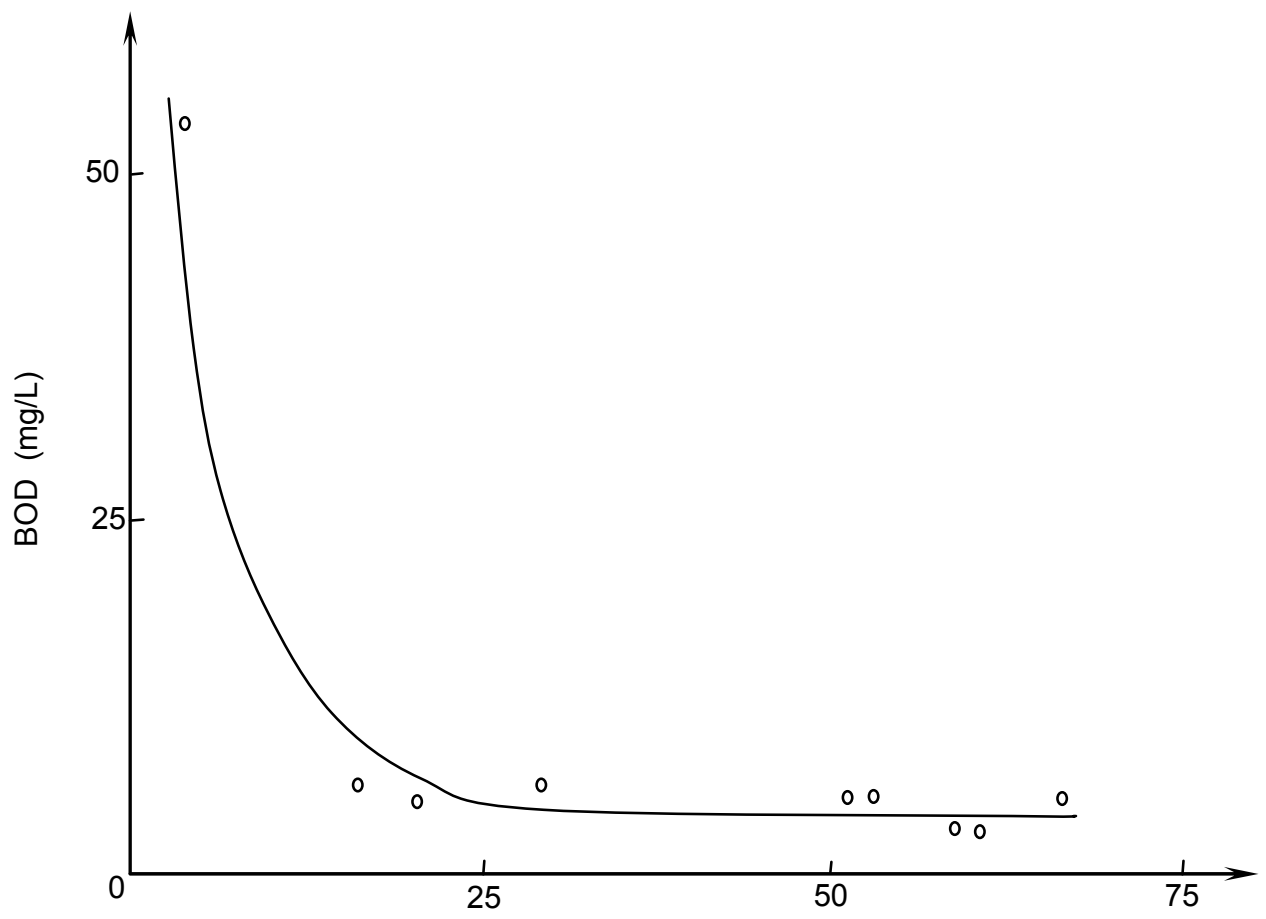

Flow rate $(\mathrm{m} 3 / \mathrm{s})$

Figure 3. Relationship between $\mathrm{BOD}_{5}$ concentrations and flow rates. 
$\frac{d L}{d t}=-\left(K_{1}+K_{3}\right) L$

$\frac{d C}{d t}=-K_{1} L+K_{2}\left(C_{5}-C\right)+K_{4}$

Given BOD and DO levels (i.e., $\mathrm{L}_{0}$ and $\mathrm{C}_{0}$ ) at the initial point $(\mathrm{t}=0)$, solutions for $\mathrm{L}$ and $\mathrm{C}$ can then be obtained as follows:

$L=L_{0} e^{-\left(K_{1}+K_{3}\right) t}$

$C=C_{5}+\left(C_{0}-C_{5}\right) e^{-K_{2} t}+\frac{K_{1} L_{0}}{K_{1}+K_{3}-K_{2}}\left[e^{-\left(K_{1}+K_{3}\right) t}-e^{-K_{2} t}\right]$

$+\left(1-e^{-K_{2} t}\right) \frac{K_{4}}{K_{2}}$

Table 3. Average BOD Concentrations (mg/L) and DO Saturation Levels (\%) in Different Seasons

\begin{tabular}{lllllll}
\hline \multirow{2}{*}{ Station } & \multicolumn{2}{c}{ Dry Season } & \multicolumn{2}{c}{ Level Season } & \multicolumn{2}{c}{ Wet Season } \\
& BOD & DO & BOD & DO & BOD & DO \\
\hline M1 & 1.79 & 5.6 & 1.52 & 83.6 & 1.49 & 93.7 \\
M2 & 5.01 & 75.5 & 1.71 & 78.6 & 2.16 & 91.6 \\
M3 & 10.37 & 54.8 & 3.83 & 79.7 & 2.37 & 96.5 \\
M4 & 50.85 & 0 & 5.10 & 67.2 & 2.58 & 87.8 \\
M5 & 5.60 & 93.3 & 2.83 & 64.6 & 2.29 & 84.1 \\
M6 & 8.00 & 129.2 & 2.96 & 74.7 & 1.77 & 81.1 \\
M8 & 4.69 & 110.0 & 2.04 & 64.9 & 1.53 & 81.6 \\
M9 & 4.95 & 106.0 & 4.57 & 85.7 & 1.93 & 80.1 \\
M10 & 9.54 & 75.9 & 7.30 & 92.5 & 2.35 & 81.5 \\
\hline
\end{tabular}

Note: The data in this table are based on five-year monitoring results.

\subsection{Formulation of Segmental Water-Quality Models}

Due to variations of hydrologic and hydraulic conditions along the river, pollutant-loading and self-purification capacities also vary in different segments of the river. Thus, one uniform modeling formulation may not be sufficient for the entire river. Instead, the river should be divided into several relatively homogeneous segments; within each of the segments, each related parameter is assumed to have a uniform property.

The study river section (60 km long) was divided into 6 segments (including D1-D2, D2-D3, D3-Baimasi, D4-D6, D6-D7, and D7-D8), according to distribution of sewage outlets and variations of the river's hydrological and environmental conditions (Figure 4). A piecewise water quality model was then initiated to reflect not only detailed hydrological and environmental characteristics of each segment but also interactions among different segments. Contaminant concentrations within each segment were assumed to be uniform. Thus, for two adjacent segments (as shown in Figure 5), a generalized mass balance expression for BOD and DO levels can be described as follows:

$$
\begin{array}{ll}
Q_{i}=Q_{i-1}+q_{i} & i=1,2, \ldots, n \\
L_{i}^{0}=\left(L_{i-1} Q_{i-1}+l_{i} q_{i}\right) / Q_{i} & i=1,2, \ldots, n \\
C_{i}^{0}=\left(C_{i-1} Q_{i-1}+c_{i} q_{i}\right) / Q_{i} & i=1,2, \ldots, n
\end{array}
$$

where $Q_{i}$ is water flow in segment $i\left(\mathrm{~m}^{3} / \mathrm{s}\right) ; q_{i}$ denotes wastewater loading to segment $i\left(\mathrm{~m}^{3} / \mathrm{s}\right) ; l_{i}$ and $c_{i}$ are BOD and DO concentrations in wastewater discharged to segment $i$, respectively $i\left(\mathrm{~g} / \mathrm{m}^{3}\right) ; L_{i}^{0}$ and $C_{i}^{0}$ denote BOD and DO concentrations at the starting point of segment $i$, respectively $\left(\mathrm{g} / \mathrm{m}^{3}\right) ; L_{i-1}$ and $C_{i-1}$ are BOD and DO concentrations at the end of segment $i-1$, respectively $\left(\mathrm{g} / \mathrm{m}^{3}\right)$. Thus, for segment $i$, we have the following BOD-DO models:

$$
\begin{aligned}
L_{i}= & L_{i}^{0} e^{-\left(K_{1 i}+K_{3 i}\right) t_{i}} \\
C_{i}= & C_{s i}+\left(C_{i}^{0}-C_{s i}\right) e^{-K_{2 i} t_{i}}+\frac{K_{1 i} L_{i}^{0}}{K_{1 i}+K_{3 i}-K_{2 i}}\left[e^{-\left(K_{1 i}+K_{3 i}\right) t_{i}}-e^{-K_{2 i} t_{i}}\right] \\
& +\left(1-e^{-K_{2 i} t_{i}}\right) \frac{K_{4 i}}{K_{2 i}}
\end{aligned}
$$

where $L_{i}$ and $C_{i}$ denote BOD and DO concentrations in segment $i(\mathrm{mg} / \mathrm{L}) ; C_{s i}$ is saturated DO concentration in segment $i$ $(\mathrm{mg} / \mathrm{L}) ; K_{l i}$ is oxygen-consumption coefficient in segment $i$ $\left(\right.$ day $\left.^{-1}\right) ; K_{2 i}$ is oxygen-recovery coefficient in segment $i\left(\right.$ day $\left.^{-1}\right)$; $K_{3 i}$ is deposition-resuspension coefficient in segment $i\left(\right.$ day $\left.^{-1}\right)$; $K_{4 i}$ is rate of oxygen production/consumption through photosynthesis and photorespiration in segment $i(\mathrm{mg} / \mathrm{L} \cdot$ day); $t$ is time for a parcel of water flowing through segment $i$ (day).

\subsection{Parameter Estimation}

Models (5a) and (5b) are calibrated based on data monitored at each segment's starting and ending points. Totally, $m$ sets of data regarding water quality, flow rate, and temperature in each segment were obtained through on-site monitoring programs. The objective of model calibration is to identify appropriate values for system parameters. This objective can be expressed as follows:

$$
\Phi\left(K_{1 i}, K_{2 i}, K_{3 i}, K_{4 i}\right)=\frac{1}{2} \sum_{j=1}^{m}\left[\alpha\left(\bar{L}_{i j}-L_{i j}\right)^{2}+(1-\alpha)\left(\bar{C}_{i j}-C_{i j}\right)^{2}\right]
$$

where $\alpha$ is a weighting parameter, $0 \leq \alpha \leq 1 ; \bar{L}_{i j}$ and $\bar{C}_{i j}$ 



Figure 4. The conceptualized Yiluo River system.

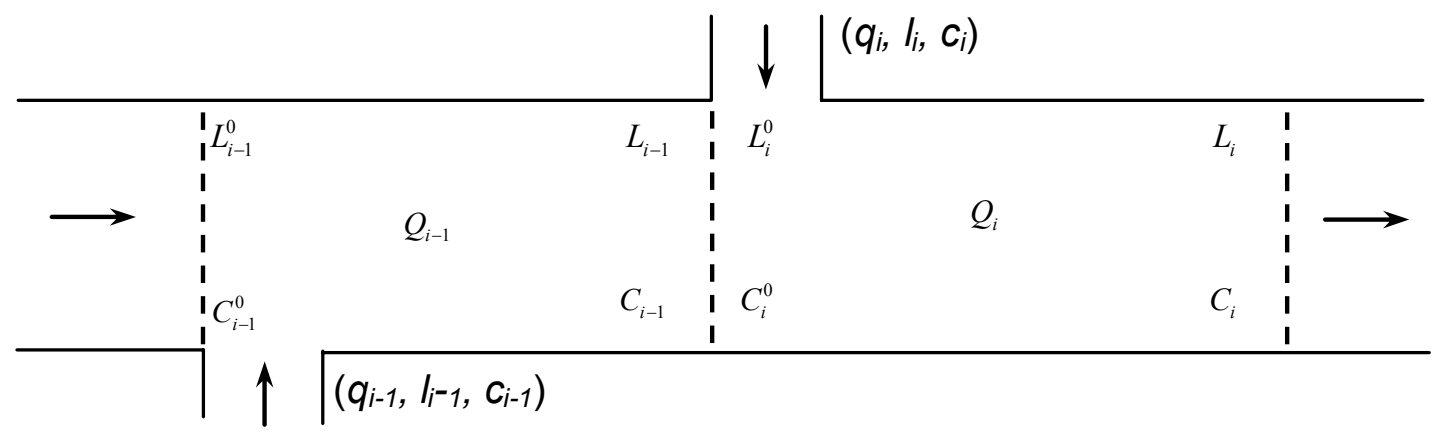

Figure 5. BOD-DO mass balance. 
represent $\mathrm{BOD}$ and $\mathrm{DO}$ concentrations obtained from equations (5a) and (5b); $L_{i j}$ and $C_{i j}$ are observed BOD and DO concentrations in segment $i$ at time $j$.

Let $\Phi\left(K_{1 i}^{*}, K_{2 i}^{*}, K_{3 i}^{*}, K_{4 i}^{*}\right)=\min \Phi\left(K_{1 i}, K_{2 i}, K_{3 i}, K_{4 i}\right)$. The obtained $K_{1 i}{ }^{*}, K_{2 i}{ }^{*}, K_{3 i}{ }^{*}$ and $K_{4 i}{ }^{*}$ values are desired parameters for segment $i$ under steady-state conditions.

Assume that flow velocities in different segments have insignificant variations in each given time interval, and can be approximated as a constant. Thus, the time required for a parcel of water passing a given segment is a constant. Therefore, equation (5) can be converted to:

$L_{i}=A_{i} L_{i}^{0}$

$C_{i}-C_{s i}=B_{i} L_{i}^{0}+E_{i}\left(C_{i}^{0}-C_{s i}\right)+D_{i}$

where:

$$
\begin{aligned}
& A_{i}=e^{-\left(K_{1 i}+K_{3 i}\right) t_{i}} \\
& B_{i}=\frac{K_{1 i}}{K_{1 i}+K_{3 i}-K_{2 i}}\left(e^{-\left(K_{1 i}+K_{3 i}\right) t_{i}}-e^{-K_{2 i} t_{i}}\right) \\
& D_{i}=\left(1-e^{-K_{2 i} t_{i}}\right) \frac{K_{4 i}}{K_{2 i}} \\
& E_{i}=e^{-K_{2 i} t_{i}}
\end{aligned}
$$

When parameters $A_{i}, B_{i}, D_{i}$ and $E_{i}$ are constants, equations (7a) and (7b) become linear functions. Thus, $A_{i}, B_{i}, D_{i}$ and $E_{i}$ can be estimated through linear regression, with the resulting $K_{l i}, K_{2 i}, K_{3 i}$ and $K_{4 i}$ values being as follows:

$$
\begin{aligned}
& K_{1 i}=-\frac{B_{i}\left(\ln A_{i}-\ln E_{i}\right)}{\left(A_{i}-E_{i}\right) t_{i}} \\
& K_{2 i}=-\frac{1}{t_{i}} \ln E_{i} \\
& K_{3 i}=-\frac{1}{t_{i}} \ln A_{i}-K_{1 i} \\
& K_{4 i}=-\frac{K_{2 i} D_{i}}{\left(1-E_{i}\right)}
\end{aligned}
$$

\begin{tabular}{|c|c|c|c|c|}
\hline \multirow[t]{2}{*}{$\begin{array}{l}\text { Monitoring } \\
\text { Program }\end{array}$} & \multicolumn{2}{|c|}{$\begin{array}{l}\text { Average Relative } \\
\text { Error (r) }(\%)\end{array}$} & \multicolumn{2}{|c|}{$\begin{array}{l}\text { Residual Standard } \\
\text { Deviation }(\mathrm{S})(\mathrm{mg} / \mathrm{L})\end{array}$} \\
\hline & BOD & DO & BOD & DO \\
\hline MP1 & 47 & 7 & 0.96 & 0.44 \\
\hline MP2 & 27 & 2. & 0.79 & 0.30 \\
\hline MP3 & 14 & 3 & 0.37 & 0.32 \\
\hline
\end{tabular}

Table 4 shows calibration results based on data of two monitoring programs. The resulting relative errors and residual standard deviations are relatively low.
Table 4. Average Relative Errors and Residual Standard Deviations for BOD and DO

\subsection{Dynamic Consideration}

Most of water pollution problems are from the discharge of organic matters to water bodies as consequences of human activities. The capability of water bodies to purify themselves is an important factor that affects water quality simulation. This self-purification capacity is dependent on water temperature and flow rate. Flow rate determines pollutant transport time and dilution ratio, and temperature is related to DO solubility in water.

The Yiluo River region has a seasonal climate. Flow rates in wet seasons are significantly different from those in dry seasons. Water temperature also varies significantly between summer and winter. In the study river section, the monthly average water temperatures are between $2.1^{\circ} \mathrm{C}$ and $25.8^{\circ} \mathrm{C}$, and the monthly average flow rates vary between 1.88 and $280 \mathrm{~m}^{3} / \mathrm{s}$. To investigate relationships between water quality and flow rate as well as water temperature, a number of monitoring programs under different flow and temperature conditions were needed. In this study, over 40 field trips for monitoring water quality in the study river section in wet, dry and level seasons were undertaken. Data of water quality under different flow and temperature conditions were obtained. Parameters $K_{l i}, K_{2 i}, K_{3 i}$ and $K_{4 i}$ were then estimated, as presented in Table 5. Based on the estimated parameters as well as the flow, temperature and water-quality data, a dynamic water quality model can be formulated with flow rate $Q$ and water temperature $T$ being variables. Thus, for a given segment $i$, parameters $K_{l i}, K_{2 i}, K_{3 i}$ and $K_{4 i}$ can be expressed as functions of $Q$ and $T$ as follows:

$$
\begin{aligned}
& K_{1 i}\left(T_{i}\right)=a_{1 i} a_{2 i}^{\left(T_{i}-20\right)} \\
& K_{2 i}\left(T_{i}, Q_{i}\right)=a_{3 i} Q_{i}^{a_{4 i}} a_{5 i}^{\left(T_{i}-20\right)} \\
& K_{3 i}\left(Q_{i}\right)=a_{6 i}+a_{7 i} Q_{i}^{-0.5} \\
& K_{4 i}\left(T_{i}, Q_{i}\right)=a_{8 i}+a_{9 i} \frac{T_{i}}{Q_{i}}
\end{aligned}
$$

where $a_{1 i}, a_{2 i}, a_{3 i}, a_{4 i}, a_{5 i}, a_{6 i}, a_{7 i}, a_{8 i}$ and $a_{9 i}$ are parameters to be estimated. Expressions for $K_{l i}$ and $K_{2 i}$ [equations (10a) and 
Table 5. Calibration Results for $K_{1}, K_{2}, K_{3}$ and $K_{4}$

\begin{tabular}{|c|c|c|c|c|c|c|c|}
\hline Section & & 1 & 2 & 3 & 4 & 5 & 6 \\
\hline \multirow[t]{6}{*}{ MP1 } & Water Temp $\left({ }^{\circ} \mathrm{C}\right)$ & 24.5 & 24.5 & 24.5 & 24.6 & 24.6 & 24.6 \\
\hline & Flow $\left(\mathrm{m}^{3} / \mathrm{s}\right)$ & 55.2 & 55.2 & 55.2 & 76.9 & 76.9 & 76.9 \\
\hline & $K_{l}$ & 1.73 & 1.73 & 1.73 & 1.49 & 1.49 & 1.49 \\
\hline & $K_{2}$ & 1.28 & 1.28 & 1.28 & 6.04 & 6.04 & 6.04 \\
\hline & $K_{3}$ & 1.50 & 1.50 & 1.50 & -0.23 & -0.23 & -0.23 \\
\hline & $K_{4}$ & 0.47 & 0.47 & 0.47 & -8.10 & -8.10 & -8.10 \\
\hline \multirow{6}{*}{$\begin{array}{l}\text { MP2 } \\
\text { (Phase 1) }\end{array}$} & Water Temp $\left({ }^{\circ} \mathrm{C}\right)$ & 24.2 & 26.6 & 28.2 & 26.8 & 28.6 & 27.7 \\
\hline & Flow $\left(\mathrm{m}^{3} / \mathrm{s}\right)$ & 7.08 & 7.50 & 7.63 & 3.31 & 3.31 & 3.39 \\
\hline & $K_{l}$ & 3.85 & 2.14 & 2.01 & 4.26 & 5.14 & 6.40 \\
\hline & $K_{2}$ & 2.68 & 2.63 & 4.41 & 15.68 & 8.48 & 5.44 \\
\hline & $K_{3}$ & 6.24 & 0.75 & 3.61 & -0.15 & -1.74 & -7.43 \\
\hline & $K_{4}$ & 1.10 & 1.67 & 33.08 & 3.37 & 27.04 & 34.90 \\
\hline \multirow{6}{*}{$\begin{array}{l}\text { MP2 } \\
\text { (Phase 2) }\end{array}$} & Water Temp $\left({ }^{\circ} \mathrm{C}\right)$ & 10.1 & 15.0 & 17.2 & 15.1 & 16.1 & 15.9 \\
\hline & Flow $\left(\mathrm{m}^{3} / \mathrm{s}\right)$ & 38.0 & 40.7 & 43.2 & 44.5 & 55.0 & 54.3 \\
\hline & $K_{l}$ & 0.02 & 1.02 & 0.78 & 3.16 & 1.48 & 5.02 \\
\hline & $K_{2}$ & 5.34 & 1.29 & 0.47 & 13.94 & 1.85 & 12.93 \\
\hline & $K_{3}$ & 4.93 & 2.39 & -0.28 & -0.41 & 2.25 & 4.60 \\
\hline & $K_{4}$ & -0.08 & 5.21 & -1.73 & -16.14 & 1.06 & -11.41 \\
\hline \multirow[t]{6}{*}{ MP3 } & Water Temp $\left({ }^{\circ} \mathrm{C}\right)$ & 15.1 & 16.3 & 21.9 & 14.6 & 19.8 & 19.4 \\
\hline & Flow $\left(\mathrm{m}^{3} / \mathrm{s}\right)$ & 16.1 & 17.2 & 22.3 & 18.3 & 31.0 & 31.1 \\
\hline & $K_{l}$ & 0.87 & 1.68 & 0.39 & 3.87 & 3.95 & 5.81 \\
\hline & $K_{2}$ & 4.32 & 0.09 & 8.93 & 6.86 & 4.59 & 3.43 \\
\hline & $K_{3}$ & 4.88 & 1.34 & 3.98 & -3.59 & -3.24 & -7.50 \\
\hline & $K_{4}$ & 0.01 & 7.23 & -28.70 & -11.51 & 3.80 & -0.01 \\
\hline
\end{tabular}

(10b)] were reported in Thackston and Krenkel (1966) and Thomann (1982). In equation (10c), $a_{6 i}$ denotes variation rate of BOD concentrations due to sedimentation and resuspension. In equation (10d), $T$ represents algae concentration which is a function of water temperature. Thus, based on the least square method, $a_{1 i}, a_{2 i}, a_{3 i}, a_{4 i}, a_{5 i}, a_{6 i}, a_{7 i}, a_{8 i}$ and $a_{9 i}$ values in each segment can be estimated, as shown in Table 6 .

\section{Stochastic Forecasting System}

In a natural river system, system state estimation is complicated by the fact that many hydrological and environmental parameters are uncertain and may be randomly disturbed by each other or by external factors. A general way to take into account these disturbances is to add some noise terms to the simulation model. However, the characteristics of the noise are usually unknown, such that the system uncertainties are often simplified in the modeling efforts. This may lead to significant estimation errors. Thus, a more realistic method is desired for effectively reflecting impacts of random disturbances on BOD and DO concentrations.

Kalman filtering technique, which is a linear recursive scheme, is well suited for real-time estimation as needed in this study. Since the Yiluo River is a naturally-evolved stream system, major interference and disturbances from most of natural and human-made processes (e.g. water pollution) could be regarded as independent stochastic events; this satisfies the basic requirement for using the Kalman filtering technique. Real-time forecasting can then be conducted through updating the previous estimates based on renewed input and output information (Kalman, 1960; Luenberger, 1969; Kwakernaak \& Sivan, 1972). The details of applying Kalman 
filtering technique to establish a stochastic BOD-DO forecasting system are described as follows.

Table 6. Calibration Results for $a_{1}, a_{2}, a_{3}, a_{4}, a_{5}, a_{6}, a_{7}, a_{8}$ and $a_{9}$

\begin{tabular}{ccccccc}
\hline Segment (i) & $\mathrm{i}=1$ & $\mathrm{i}=2$ & $\mathrm{i}=3$ & $\mathrm{i}=4$ & $\mathrm{i}=5$ & $\mathrm{i}=6$ \\
\hline$a_{1}$ & 0.71 & 1.59 & 0.73 & 3.80 & 2.73 & 5.60 \\
$a_{2}$ & 1.37 & 1.04 & 1.11 & 1.01 & 1.09 & 1.01 \\
$a_{3}$ & 2.06 & 0.21 & 18.46 & 2.22 & 3.10 & 6.42 \\
$a_{4}$ & 0.20 & 0.37 & -0.72 & 0.69 & 0.03 & 0.01 \\
$a_{5}$ & 1.01 & 1.19 & 1.07 & 1.17 & 1.12 & 1.09 \\
$a_{6}$ & -0.56 & 3.41 & -1.15 & 3.42 & 1.72 & 4.81 \\
$a_{7}$ & 18.84 & -7.49 & 12.95 & -29.58 & -6.18 & -22.42 \\
$a_{8}$ & 0.66 & 0.37 & 10.28 & 2.00 & 3.01 & 5.38 \\
$a_{9}$ & -0.23 & 0.34 & -4.95 & -12.88 & 1.01 & -8.78 \\
\hline
\end{tabular}

\subsection{State Estimation Equations}

Let $\delta_{L_{i}}$ and $\delta_{C_{i}}$ be random variables, standing for errors of BOD and DO concentrations in segment $i$ due to random disturbance, respectively. Both of them are assumed to have normal distributions [i.e. $N\left(0, \sqrt{\sigma_{L_{i}}}\right)$ for $\delta_{L_{i}}$ and $N\left(0, \sqrt{\sigma_{C_{i}}}\right)$ for $\left.\delta_{C_{i}}\right]$. Thus, the relevant covariance matrix $\left(Q_{i}\right)$ can be defined as:

$Q_{i}=\left[\begin{array}{cc}\sigma_{L_{i}} & 0 \\ 0 & \sigma_{C_{i}}\end{array}\right]$

Based on mass balance Equations (4a) to (4c) and (7a) to (7b), water quality model (7) can be converted to:

$$
\begin{aligned}
L_{i+1}= & \frac{Q_{i}}{Q_{i+1}} A_{i+1} L_{i}+\frac{q_{i+1}}{Q_{i+1}} A_{i+1} l_{i+1}+\delta_{L_{i+1}} \\
C_{i+1}-C_{s, i+1}= & \frac{Q_{i}}{Q_{i+1}}\left(B_{i+1} L_{i}+E_{i+1} C_{i}\right)+ \\
& \frac{q_{i+1}}{Q_{i+1}}\left(B_{i+1} l_{i+1}+E_{i+1} C_{i}\right)-E_{i+1} C_{s, i+1}+D_{i+1}+\delta_{C_{i+1}}
\end{aligned}
$$

where $L_{i+1}$ denotes BOD concentration in segment $i+1 ; C_{i+1}-$ $C_{s, i+I}$ represents oxygen deficiency.

Let $C_{i+1}$ represent $C_{i+1}-C_{s, i+1}$, we can then convert equations (12a) and (12b) into the following matrix format:

$$
\left[\begin{array}{l}
L_{i+1} \\
C_{i+1}
\end{array}\right]=\Phi_{i+1, i}\left[\begin{array}{l}
L_{i} \\
C_{i}
\end{array}\right]+\left[\begin{array}{l}
F_{L_{i+1}} \\
F_{C_{i+1}}
\end{array}\right]+\left[\begin{array}{c}
\delta_{L_{i+1}} \\
\delta_{C_{i+1}}
\end{array}\right]
$$

where

$$
\begin{aligned}
& \Phi_{i+1, i}=\frac{Q_{i}}{Q_{i+1}}\left[\begin{array}{cc}
A_{i+1} & 0 \\
B_{i+1} & E_{i+1}
\end{array}\right] \\
& {\left[\begin{array}{l}
F_{L_{i+1}} \\
F_{C_{i+1}}
\end{array}\right]=\left[\begin{array}{c}
\frac{q_{i+1}}{Q_{i+1}} A_{i+1} l_{i+1} \\
\frac{q_{i+1}}{Q_{i+1}}\left(B_{i+1} l_{i+1}+E_{i+1} c_{i+1}\right)-E_{i+1} C_{s, i+1}+D_{i+1}
\end{array}\right]}
\end{aligned}
$$

Let $V_{L_{i}}$ and $V_{C_{i}}$ represent measurement errors for BOD and DO concentrations in segment $i$, respectively. They are assumed to have normal distributions with $N\left(0, \sqrt{r_{L_{i}}}\right)$ for $V_{L_{i}}$ and $N\left(0, \sqrt{r_{C_{i}}}\right)$ for $V_{C_{i}}$. Their mean values equal zero, and the relevant covariance matrix is:

$R_{i}=\left[\begin{array}{cc}r_{L_{i}} & 0 \\ 0 & r_{C_{i}}\end{array}\right], \quad i=1,2, \ldots, n$

Thus, a state estimation equation that considers the measurement errors can be expressed as follows:

$\left[\begin{array}{c}Z_{L_{i}} \\ Z_{C_{i}}\end{array}\right]=\left[\begin{array}{c}L_{i} \\ C_{i}\end{array}\right]+\left[\begin{array}{c}V_{L_{i}} \\ V_{C_{i}}\end{array}\right], \quad i=1,2, \ldots, n$

where $\left[\begin{array}{l}Z_{L_{4}} \\ Z_{C_{4}}\end{array}\right]$ are observed BOD and DO concentrations in segment $i ;\left[\begin{array}{l}L_{i} \\ C_{i}\end{array}\right]$ are real values of BOD and DO concentrations. Since equations (13) and (16) represent linear systems, the Kalman filtering technique can be employed to carry out system state estimation.

Firstly, let $\hat{L}_{i, i}$ and $\hat{C}_{i, i}$ represent estimated BOD and DO concentrations in segment $i$, based on the observed BOD and DO concentrations from segment 1 to $i$; let $\hat{L}_{i+l, i}$ and $\hat{C}_{i+l, i}$ represent forecasted BOD and DO concentrations in segment $i+l$, based on the observed BOD and DO levels from the former $i$ segments. Assume that the observed BOD and DO concentrations $\left[\begin{array}{l}L_{0} \\ C_{0}\end{array}\right]$ at the reference segment exactly equal $\begin{aligned} & L_{0,0} \\ & \hat{C}_{0,}\end{aligned}$. Then, the recursive scheme based on the Kalman filtering technique can be described as follows:

(a) State estimation equation:

$\left[\begin{array}{l}\hat{L}_{i+1, i} \\ \hat{C}_{i+1, i}\end{array}\right]=\Phi_{i+1, i}\left[\begin{array}{l}\hat{L}_{i, i} \\ \hat{C}_{i, i}\end{array}\right]+\left[\begin{array}{l}F_{L_{i+1}} \\ F_{C_{i+1}}\end{array}\right]$ 
(b) Covariance matrix of estimation errors:

$$
P_{i+1, i}=\Phi_{i+1, i} P_{i, i} \Phi^{T}{ }_{i+1, i}+Q_{i+1}
$$

(c) Gain matrix of the filter:

$K_{i+1}=P_{i+1, i}\left[P_{i+1, i}+R_{i+1}\right]^{-1}$

(d) State filtering equation:

$$
\left[\begin{array}{l}
\hat{L}_{i+1, i+1} \\
\hat{C}_{i+1, i+1}
\end{array}\right]=\left[\begin{array}{l}
\hat{L}_{i+1, i} \\
\hat{C}_{i+1, i}
\end{array}\right]+K_{i+1}\left(\left[\begin{array}{l}
Z_{L_{i+1}} \\
Z_{C_{i+1}}
\end{array}\right]-\left[\begin{array}{l}
\hat{L}_{i+1, i} \\
\hat{C}_{i+1, i}
\end{array}\right]\right)
$$

(e) Covariance matrix of filtering errors:

$$
P_{i+1, i+1}=\left(I-K_{i+1}\right) P_{i+1, i} \quad \text { (where } I \text { is a unit matrix) }
$$

(f) Forecasting equation:

$$
\left[\begin{array}{l}
\hat{L}_{i+1, i} \\
\hat{C}_{i+1, i}
\end{array}\right]=\Phi_{i+l, i}\left[\begin{array}{l}
\hat{L}_{i, i} \\
\hat{C}_{i, i}
\end{array}\right]+\sum_{K=1}^{l-1} \Phi_{i+l, i+k}\left[\begin{array}{l}
F_{L_{i+k}} \\
F_{C_{i+k}}
\end{array}\right]+\left[\begin{array}{c}
F_{L_{i+1}} \\
F_{C_{i+1}}
\end{array}\right]
$$

where

$\Phi_{i+l, i+k}=\prod_{j=K}^{l-1} \Phi_{i+j+1, i+j}, \quad i=0,1, \ldots, n-1$

Equations (17) to (22) form the stochastic water-quality forecasting system. Given $\left[\begin{array}{l}\hat{L}_{0,0} \\ \hat{C}_{0,0}\end{array}\right], P_{0,0}, Q_{i}$ and $R_{i}$, optimal state estimates of BOD and DO concentrations for the study river section can then be obtained.

\subsection{Self-Adaptive Technique for Automatic System Rectification}

Since covariances $\sigma_{L_{L}}$ and $\sigma_{C_{i}}$ of random variables $\delta_{L(i)}$ and $\delta_{C(i)}$ can not be estimated precisely in advance, the Kalman filtering scheme cannot be constantly maintained at the optimal state. Therefore, an optimality test is required for automatic rectification of the forecasting system. In this study, a self-adaptive technique is used for approaching the desired optima.

Firstly, let array $\left[\begin{array}{l}v_{L} \\ v_{C}\end{array}\right]$ represent the differences between observed and estimated BOD and DO levels:

$\left[\begin{array}{c}v_{L_{i+1}} \\ v_{C_{i+1}}\end{array}\right]=\left[\begin{array}{l}Z_{L_{i+1}} \\ Z_{C_{i+1}}\end{array}\right]-\left[\begin{array}{l}\hat{L}_{i+1, i} \\ \hat{C}_{i+1, i}\end{array}\right], \quad i=0,1, \cdots, n-1$
The operation status of a filtering scheme can then be examined based on this array and the covariance matrix of estimation errors $\left(Q_{i}\right)$. The following are the details:

(1) Test and rectification of array expectation

According to Kalman (1960), when the filtering scheme is operated at the optimal state, we should have:

$H_{0}: E\left\{\left[\begin{array}{c}v_{L} \\ v_{C}\end{array}\right]\right\}=0$

where $E\left\{\left[\begin{array}{l}v_{L} \\ v_{C}\end{array}\right]\right\}$ defines the expectation of array $\left[\begin{array}{l}v_{L} \\ v_{C}\end{array}\right]$.

Thus, If $E\left\{\left[\begin{array}{l}v_{L} \\ v_{C}\end{array}\right]\right\} \neq 0$, it can be judged that the filtering scheme does not work optimally, and rectification to optimal status is required. A covariance matrix of $\left[\begin{array}{l}v_{L_{i}} \\ v_{C_{i}}\end{array}\right]$ should then be established as follows:

$\sum v_{i+1}=P_{i+1, i}+R_{i+1} \quad, \quad i=0,1, \cdots, n-1$

A statistic can be calculated:

$\chi_{2 n}^{2}=\sum_{i=1}^{n}\left(v_{L_{i}}, v_{C_{i}}\right)\left(\sum v_{i+1}\right)^{-1} \cdot\left[\begin{array}{c}v_{L_{i}} \\ v_{C_{i}}\end{array}\right]$

Since the study river section is divided into 3 segments in the upstream of Baimasi and another three in the downstream of Tazhuang, $n$ should be equal to 3 . If the significance level $(\alpha)$ is set as $0.05, \chi_{\alpha}^{2}$ would be 12.592 . Thus, if $\chi_{2 n}^{2}<\chi_{\alpha}^{2}=12.592$, the original assumption $H_{0}: E\left\{\left[\begin{array}{l}v_{L} \\ v_{C}\end{array}\right]\right\}=0$ can be accepted, and the filtering scheme is considered ${ }_{L_{i}}^{\text {Working at }}$ its optimal state. Otherwise, the initial values in $\left[\begin{array}{l}L_{i, i} \\ \hat{C}_{i, i}\end{array}\right]$ should be re-examined and rectified as follows.

Let:

$\left[\begin{array}{c}\hat{L}_{i, i}^{*} \\ \hat{C}_{i, i}^{*}\end{array}\right]=\left[\begin{array}{l}\hat{L}_{i, i} \\ \hat{C}_{i, i}\end{array}\right]+\left[\begin{array}{c}\Delta \hat{L}_{i, i} \\ \Delta \hat{C}_{i, i}\end{array}\right]$

where $\left[\begin{array}{c}\Delta \hat{L} \\ \Delta \hat{C}\end{array}\right]$ denotes rectification amounts, and $\left[\begin{array}{l}\hat{L}^{*} \\ \hat{C}^{*}\end{array}\right]$ denotes rectified initial values.

Thus, a new array can be obtained as follows:

$\left[\begin{array}{l}v_{L_{i+1}}^{*} \\ v^{*}{ }_{C_{i+1}}^{*}\end{array}\right]=\left[\begin{array}{l}Z_{L_{i+1}} \\ Z_{C_{i+1}}\end{array}\right]-\left[\begin{array}{l}\hat{L}_{i+1, i}^{*} \\ \hat{C}_{i+1, i}^{*}\end{array}\right]$

When the new array's expectation is zero, the filtering scheme is considered working properly. 
(2) Test and rectification of covariance matrix $Q_{(i)}$

Define residual term in the $l$-th forecasting step as a l-dimensional vector:

$\bar{d}_{i+l}=\left[\begin{array}{l}Z_{L_{i+1}} \\ Z_{C_{i+1}}\end{array}\right]-\left[\begin{array}{l}\hat{L}_{i+l, i} \\ \hat{C}_{i+l, i}\end{array}\right], \quad i=0,1, \cdots, n-1 ; i+1 \leq n$

Let:

$\bar{d}_{i, N}=\left[\begin{array}{l}\bar{d}_{i+1} \\ \bar{d}_{i+2} \\ \cdots \cdots \\ \bar{d}_{i+N}\end{array}\right] \quad i=0,1, \cdots, n-1 ; i+1 \leq n$

Define a $2 N \times 2 N$ matrix as follows:

$W_{0 i}=W_{0 i}^{(1)}+W_{0 i}^{(2)} \quad i=0,1, \cdots, n-1$

where:

$W_{0 i}^{(1)}=W_{i r s}^{(1)} \quad \forall i, r, s ; \quad r \geq 1, s \leq N$

$W_{r s}^{(1)}=\Phi_{i+r, i} P_{i, i} \Phi_{i+s, i}^{T}+R_{i+r} \delta_{r s} \quad i=0,1, \cdots, n-1 ; \forall r, s$

$\delta_{r s}=\left\{\begin{array}{ll}1 & (r=s) \\ 0 & (r \neq s)\end{array} \quad \forall r, s\right.$

$W_{0 i}^{(2)}=W_{i r s}^{(2)} \quad \forall i, r, s ; r \geq 1, s \leq N$

$W_{i r s}^{(2)}=\sum_{j=i}^{i-1+\min (r, s)} \Phi_{i+r, j} Q_{0, j} \Phi_{i+s, j}^{T} \quad i=0,1, \cdots, n-1 ; \forall r, s$

$\Phi_{i+r, i}=\prod_{j=1}^{r} \Phi_{i+j, i} \quad i=0,1, \cdots, n-1 ; \forall r ; r \leq n-i$

In (36), $Q_{0, j}$ represents initial covariance matrix for recursive estimation. Thus, a statistic for each $i$ can be calculated as follows:

$Y_{i}=\bar{d}_{i, N}^{T}, W_{0 i}^{-1} \bar{d}_{i, N} \quad \forall i$

The above statistic has a $\chi^{2}$ distribution with its degree of freedom being $2 N$. If the significance level $(\alpha)$ is set as 0.10 , pair $\chi_{1, a / 2}^{2}$ and $\chi_{2, a / 2}^{2}$ can be obtained. Table 7 shows acceptable ranges of the $Y_{i}$ statistic. When $\chi_{1, a / 2}^{2} \leq Y_{i} \leq$ $\chi_{2, a / 2}^{2}$, the obtained $Q_{0(j+1)}$ is acceptable, such that further test and rectification are not required. Otherwise, further test and rectification should be carried out as follows.

$W_{0 i}=\bar{d}_{i, N} \cdot \bar{d}_{i, N}^{T}$

Based on equation (31), we have:

$W_{0 i}^{(2)}=\bar{d}_{i, N} \cdot \bar{d}_{i, N}^{T}-W_{0 i}^{(1)} \quad i=0,1,2, \cdots, n-1$

The right-hand sides of equation (40) are independent of $Q_{i}$, while its left-hand sides are functions of $Q_{i}$. Thus, a linear equation group for $Q_{i}$ can be obtained through comparing corresponding terms in the right- and left-hand sides of equation (40). Then, using the least square method, the linear equation group can be solved for obtaining estimations of $Q_{i}$, which represent the rectified covariance matrix of estimation errors.

Table 7. Acceptable Intervals of $Y_{i}$

\begin{tabular}{ll}
\hline $\mathrm{N}$ & Acceptable range of $Y_{i}$ \\
\hline 3 & $1.635 \leq Y_{i} \leq 12.592$ \\
2 & $0.711 \leq Y_{i} \leq 9.488$ \\
1 & $0.103 \leq Y_{i} \leq 5.991$ \\
\hline
\end{tabular}

\subsection{Result and Discussion}

The developed forecasting system was used for estimating BOD and DO levels at the segments of Anlewo, Shifangyuan, and Baimasi. Two on-site monitoring programs (MP1 and MP2) were undertaken to observe BOD and DO concentrations, with the results being used for error analyses. A covariance matrix of measurement errors was established based on the sampling and laboratory-analysis techniques:

$R=\left[\begin{array}{lc}0.05 & 0 \\ 0 & 0.01\end{array}\right]$

The initial estimation of $Q$ was set as:

$Q=\left[\begin{array}{lr}0.1 & 0 \\ 0 & 0.1\end{array}\right]$

With the self-adaptive technique as described in section 4.3 , optimality of the filtering scheme is continuously tested and rectified for maintaining desired states. Analyses of relative errors between observed and forecasted (model-based and filter-based) BOD and DO concentrations were carried out for the segments of Anlewo (M2), Shifangyuan (M3), and Baimasi (M5). Data from two monitoring programs were used to verify the forecasting results; each monitoring program gener 
Table 8. Relative Errors between Observed and Forecasted BOD Concentrations

\begin{tabular}{|c|c|c|c|c|c|c|c|c|c|c|c|c|c|c|c|c|}
\hline \multirow{3}{*}{ No. } & \multirow{3}{*}{ MP } & \multicolumn{5}{|c|}{ Anlewo } & \multicolumn{5}{|c|}{ Shifangyuan } & \multicolumn{5}{|c|}{ Baimasi } \\
\hline & & State & & & Filter & & State & & & Filter & & State & & & Filter & \\
\hline & & OBS & $\mathrm{MBF}$ & RE (\%) & FBF & RE $(\%)$ & OBS & $\mathrm{MBF}$ & $\mathrm{RE}(\%)$ & FBF & RE (\%) & OBS & $\mathrm{MBF}$ & $\mathrm{RE}(\%)$ & FBF & RE $(\%)$ \\
\hline 1 & MP11 & 2.38 & 1.292 & 45.7 & 2.329 & 2.1 & 4.00 & 4.192 & 4.8 & 4.009 & 0.2 & 2.96 & 3.114 & 5.2 & 2.971 & 0.4 \\
\hline 2 & MP12 & 2.20 & 1.985 & 9.6 & 2.189 & 0.5 & 3.26 & 4.090 & 25.4 & 3.302 & 1.3 & 3.28 & 2.807 & 14.4 & 3.247 & 1.0 \\
\hline 3 & MP13 & 1.86 & 1.650 & 30.6 & 1.849 & 0.6 & 3.76 & 3.844 & 2.2 & 3.746 & 0.1 & 3.26 & 3.008 & 7.7 & 3.243 & 0.5 \\
\hline 4 & MP21 & 1.02 & 1.749 & 71.5 & 1.051 & 3.0 & 3.98 & 2.953 & 10.3 & 3.927 & 1.3 & 2.70 & 2.700 & 0 & 2.700 & 0 \\
\hline 5 & MP22 & 1.56 & 1.657 & 6.2 & 1.563 & 0.2 & 4.00 & 3.325 & 16.9 & 3.965 & 0.9 & 2.60 & 2.717 & 4.5 & 2.608 & 0.3 \\
\hline 6 & MP23 & 1.22 & 1.749 & 43.4 & 1.242 & 1.8 & 3.98 & 3.092 & 22.3 & 3.934 & 1.2 & 2.50 & 2.704 & 8.2 & 2.514 & 0.6 \\
\hline
\end{tabular}

Note: $\mathrm{MP}=$ monitoring program; $\mathrm{OBS}=$ observed values; $\mathrm{MBF}=$ model-based forecasted values; $\mathrm{FBF}=$ filter-based forecasted values; $\mathrm{RE}=$ relative error; MP11, MP12, and MP13 = samples 1, 2, and 3 in MP1, respectively; MP21, MP22, and MP23= samples 1, 2, and 3 in MP2, respectively.

Table 9. Relative Errors between Observed and Forecasted DO Concentrations

\begin{tabular}{|c|c|c|c|c|c|c|c|c|c|c|c|c|c|c|c|c|}
\hline \multirow[t]{3}{*}{ No. } & \multirow[t]{3}{*}{ MP } & \multicolumn{5}{|c|}{ Anlewo } & \multicolumn{5}{|c|}{ Shifangyuan } & \multicolumn{5}{|c|}{ Baimasi } \\
\hline & & \multicolumn{3}{|l|}{ State } & \multicolumn{2}{|l|}{ Filter } & \multicolumn{3}{|l|}{ State } & \multicolumn{2}{|l|}{ Filter } & \multicolumn{3}{|l|}{ State } & \multicolumn{2}{|l|}{ Filter } \\
\hline & & OBS & $\mathrm{MBF}$ & RE (\%) & FBF & RE (\%) & OBS & $\mathrm{MBF}$ & RE (\%) & FBF & RE (\%) & OBS & $\mathrm{MBF}$ & RE (\%) & FBF & RE (\%) \\
\hline 1 & MP11 & 7.63 & 8.365 & 9.6 & 7.648 & 0.2 & 7.54 & 6.960 & 7.7 & 7.509 & 0.4 & 5.69 & 5.489 & 3.5 & 5.689 & 0 \\
\hline 2 & MP12 & 7.79 & 8.310 & 6.7 & 7.800 & 0.1 & 7.94 & 7.219 & 9.1 & 7.902 & 0.5 & 5.51 & 5.576 & 1.2 & 5.510 & 0 \\
\hline 3 & MP13 & 7.93 & 8.406 & 6.0 & 7.939 & 0.1 & 7.81 & 7.465 & 4.4 & 7.792 & 0.2 & 5.46 & 5.616 & 2.9 & 5.461 & 0 \\
\hline 4 & MP21 & 7.27 & 7.837 & 7.8 & 7.281 & 0.1 & 7.06 & 7.372 & 4.4 & 7.076 & 0.2 & 5.61 & 5.130 & 8.6 & 5.609 & 0 \\
\hline 5 & MP22 & 7.41 & 7.792 & 5.2 & 7.417 & 0.1 & 7.07 & 7.431 & 5.1 & 7.089 & 0.3 & 5.59 & 5.132 & 8.2 & 5.589 & 0 \\
\hline 6 & MP23 & 7.47 & 7.913 & 5.9 & 7.472 & 0 & 7.20 & 7.611 & 5.7 & 7.222 & 0.3 & 5.68 & 5.157 & 9.2 & 5.679 & 0 \\
\hline
\end{tabular}

Note: $\mathrm{MP}=$ monitoring program; $\mathrm{OBS}=$ observed values; $\mathrm{MBF}=$ model-based forecasted values; $\mathrm{FBF}=$ filter-based forecasted values; $\mathrm{RE}=$ relative error; MP11, MP12, and MP13 = samples 1, 2, and 3 in MP1, respectively; MP21, MP22, and MP23= samples 1, 2, and 3 in MP2, respectively. 
ates three samples for each segment. Three sets of data for observed and forecasted BOD and DO concentrations were examined, with the resulting relative errors being shown in Tables 8 and 9. The relative errors between observed (in MP1) and predicted (model-based) BOD concentrations for three samples in the Anlewo Segment are $45.7 \%, 9.6 \%$, and $30.6 \%$, with an average of $28.6 \%$; in comparison, the errors between observed (in MP1) and predicted (filter-based) BOD concentrations are only $2.1 \%, 0.5 \%$, and $0.6 \%$, with an average of $1.1 \%$. For samples obtained in MP2, the average error between observed and predicted (model-based) values is $40.4 \%$, while that between observed and predicted (filter-based) values is $1.7 \%$. Table 9 presents the result of error analysis for the predicted DO concentrations. The average errors between observed and predicted (model-based) DO concentrations in the Anlewo Segment are $7.4 \%$ and $6.3 \%$ for results of MP1 and MP2, respectively; and those between observed and predicted (filter-based) DO levels are $0.13 \%$ and $0.07 \%$ for results of MP1 and MP2, respectively. The results indicate that the filter-based approach can lead to much improved prediction accuracy. Similar phenomena can also be found for results of the other segments as shown in Tables 8 and 9. The results indicate that the Kalman filtering technique can effectively reflect the randomness of the study system, such that improved accuracy of water quality prediction can be achieved.

\section{Conclusions}

In this study, a stochastic water-quality forecasting system was developed for the Yiluo River, a tributary of the Yellow River with extremely high sediment and suspended-solid loadings. Extensive investigations of water quality in the river and the related pollution sources and watershed conditions were conducted. A modified Dobbins BOD-DO model was developed to simulate water quality in the river, with interrelationships among water quality and the related source and sink conditions being explicated. The developed model was calibrated through examination of data from historical records and specific field studies. A stochastic water-quality forecasting system was then developed to reflect random characteristics of many parameters, based on Kalman-filtering and self-adaptive techniques.

The developed system was used for predicting DO and BOD levels in the Yiluo River. The results indicated that randomness in many system parameters and their interactions had been effectively handled; the accuracy of state estimation was generally satisfactory. The modeling system is useful for regional water quality management. The resulting water quality predictions would provide decision support for the planning of related pollution abatement activities.

This study is a new attempt to develop a water quality forecasting system for northern China rivers where loadings of organic pollutants and suspended solids are extremely high and uncertainties exist in many system parameters. Further studies that incorporate techniques of fuzzy simulation and real-time process modeling would be helpful for more effec- tively reflecting the system's uncertain and dynamic features and thus improving the forecasting accuracy.

Acknowledgments. This research has been supported by the Natural Sciences and Engineering Research Council of Canada.

\section{References}

Beck, M.B. and Young, P.C. (1976). Systematic identification of DO-BOD model structure. Environ. Eng., 120(EE5), 909-907.

Belanger, T.V. (1980). Benthic oxygen demain in Lake Apopka Florida. Water Res., 15, 267-274.

Bobbie, J.E. and Tiwari, J.L. (1978). Econsystem models vs biological reality: Experiences in the systems analysis of an Artic pond. Verh. Internat. Verein. Limnol., 20, 105-109.

Dewey, R.J. (1984). Application of stochastic dissolved oxygen model. J. Environ. Eng., 110(2), 412-429.

Di Toro, D.M. and O'Connor, D.J. (1968). The distribution of dissolved oxygen in a stream with time varying velocity. Water Resour. Res., 4, 639-646.

Dobbins, W.E. (1964). BOD and oxygen relationships in streams, $J$. San, Eng. Div., Proc., 90, 58-73.

Fillos, J. and Swanson, W.R. (1975). The release rate of nutrients from river and lake sediments. J. Water Pollut. Control Fed., 47, 1032-1042.

Finney, B.A., Bowles, D.S. and Windham, M.P. (1982). Random differential equations in river water quality modeling. Water Resour. Res., 18(1), 112-134.

Kalman, R.E. (1960). A new approach to linear filtering and prediction problems. Trans. ASME, Series D, J. Basic Eng., 32, 34-45.

Kwakernaak, H. and Sivan, R. (1972). Linear Optimal Control Systems, John Wiley, New York.

Leduc, R., Unny, T.E. and McBean, E.A. (1986). Stochastic model of first-order BOD kinetics. Water Res., 20(5), 625-632.

Loucks, D.P. and Lynn, W.R. (1966). Probabilistic models for predicting stream quality. Water Resour. Res., 2(3), 593-605.

Luenberger, D.G. (1969). Optimization by Vector Space Method, John Wiley, New York.

McCutcheon, S.C. (1989). Water Quality Modeling: Volume I, Transport and Surface Exchange in Rivers, CRC Press, Boca Raton, Florida, USA.

Brown, L.C. and Barnwell, T.O. (1987). The Enhanced Stream Water Quality Models QUAL2E and QUAL2E-UNCAS: Documentation and Users Mannual, US Environmental Protection Agency, Georgia, USA.

Orlob, G.T. (1992). Water quailty moeling for decision making. $J$. Water Resour. Plann. Manage., 118, 295-307.

Ponambalam, K. and Curi, W.F. (1991). Stochastic BOD-DO modeling revisited, Technical Report No. 484-X-240791, Dept. of Systems Desing Engineering, University of Waterloo, Canada.

Rinaldi, S. and Soncini-Sessa, R. (1978). Sensitivity analysis of generalized Streeter-Phelps models. Adv. Water Resour., 1, 141-146.

Shastry, J.S., Fan, L.T. and Erickson, L.E. (1975). Nonlinear parameter estimation in water quality modeling. J. Environ. Eng. Div., 99, 315-331

Shih, C.S. (1975). Stochastic water quality by simulation. Water Res. Bull., 11(3), 256-266.

Song, B.Q. and Brown, L.C. (1990). DO model undertainty with correlated inputs. J. Environ. Eng., 116(6), 1164-1180.

Steeter, H.W. and Phelps, E.B. (1925). A study on the pollution and natural purification of the Ohio River, US Public Health Service, Public Health Bulletin, No. 146, Washington, DC, USA. 
Thackston, I.E. and Krenkel, P.A. (1966). Longitudinal Mixing and Reaeration In Natural Streams, Ph.D. Dissertation, Vanderbilt University, Nashville, TN, USA.

Thomann, R.U. (1982). Verification of water quality models. $J$. Environ. Eng. Div., 108(EE5), 932-910.

Thomas, H.A. (1948). Pollution load capacity of streams. Water Sewage Works, 95, 405.

Tiwaris, J.L., Hobbie, J.E., Reed, J.P., Stanley, D.W. and Miller, M.C. (1979). Some stochastic differential equations as models ecosystems: Monte Carlo simulation approach. Math. Biosci., $28,25-44$.

Tung, Y.K. and Hathorn, W.E. (1988). Assessment of probability distribution of dissolved oxygen deficit. J. Environ. Eng., 114(6), 1421-1435.

Young, P. and Beck, B. (1974). The modeling and control of water quality in a river system. Automatica, 10, 455-468.

Zielinsky, P.A. (1989). Stochastic dissolved oxygen model. $J$. Environ. Eng., 114(1), 74-90. 